Western University

Scholarship@Western

Department of Economics Research Reports

Economics Working Papers Archive

1980

Intermediate Goods and the Incidence of the Corporation Income Tax

Kul B. Bhatia

Follow this and additional works at: https://ir.lib.uwo.ca/economicsresrpt

Part of the Economics Commons

Citation of this paper:

Bhatia, Kul B.. "Intermediate Goods and the Incidence of the Corporation Income Tax." Department of Economics Research Reports, 8020. London, ON: Department of Economics, University of Western Ontario (1980). 
ISSN: $\quad 0318-725 \mathrm{X}$

ISBN: $\quad 0-7714-0237-6$

RESEARCH REPORT 8020

INTERMEDIATE GOODS AND THE INCIDENCE

OF THE CORPORATION INCOME TAX

by

Ku1 B. Bhatia

December, 1980

Depertnent of Economics Libran

DEC $1 \leq 19980$

- University of Western Ontario 


\section{INTERMEDIATE GOODS AND THE INCIDENCE OF THE \\ CORPORATION INCOME TAX}

by

Kul B. Bhatia*

The purpose of this paper is to examine how intermediate goods affect the Incidence of the corporation income tax (CIT). Most writing on this subject assume that an economy produces only final goods. Harberger (1962), for example, divides the economy into two sectors--a corporate sector consisting primarily of manufacturing, and a noncorporate sector comprising mainly of agriculture--each producing a final good. Such assumptions simplify analysis, but they cannot always be supported by facts. Leontief (1965), in an inputoutput study of the U.S. economy shows that almost one third of the output of agriculture is used for producing other goods, largely in manufacturing industry, or in the corporate sector according to the Harberger classification. If this aspect of the structure of production is left out of tax-incidence studies, the results can be seriously misleading. ${ }^{1}$ Questions about the inctdence of CIT, therefore, deserve another look.

We focus here on pure intermediate goods only, i.e., goods which do not satisfy any final demand. The theoretical framework is the same as Harberger's, except that an intermediate good, used up entirely in producing the two final goods, is introduced. For simplicity it is assumed that there are no taxes of any sort on the intermediate good. This model takes us a step closer to reality, but it considerably complicates the analysis. For instance, in the Harberger specification, capital can be substituted only for labor. Now there is a third good which also uses these factors of production and which, in turn, can be substituted for 
capital and labor in the production of final goods. The two final goods thus use capital and labor directly, as in the Harberger formulation, and indirectly via the intermediate good, so the apparent or direct factor intensity is likely to differ from the gross capital-labor ratio. Instead of a direct elasticity of substitution between labor and capital, we now have six partial elasticities of substitution, and many other complications come into play. The analysis leads to a reformulation of many conclusions derived from models with only final goods. Some of these results do not hold when intermediate goods are introduced and existing empirical estimates also have to be revised.

The model is outlined in the next section where a general solution is also derived. In Section III we present several analytical results about tax-incidence involving intermediate goods. Various Harberger propositions which need to be modified are also discussed there. Some empirical estimates for the U.S. economy are reported in Section IV, and a few simulation results are set out in Section $v$.

\section{THE MODEL}

We assume two final goods $X_{1}$ and $X_{2}$ and a pure intermedlate good $M$ which is fully used up in the production of $x_{1}$ and $x_{2}$. Labor $(L)$ and capital $(K)$ are two primary factors with fixed endowments. $X_{1}$ is produced in the corporate sector. The only tax in the system is CIT levied on capital used directly in producing $x_{1}\left(K_{1}\right)$. Net return to capital in industry $i$ is denoted by $r_{i}$ and $\operatorname{trk}_{i}$ is the total tax revenue. It is also assumed that $a 11$ production functions are homogeneous of degree one and there is full employment of factors and perfect competition. Competition ensures that factor prices, net of tax, are equalized across industries. The following equations can be specified: 
Ful1-employment Conditions

$$
\begin{aligned}
& a_{L 1} x_{1}+a_{L 2} x_{2}+a_{L M} M=L \\
& a_{K 1} x_{1}+a_{K 2} x_{2}+a_{K M} M=K \\
& a_{M 1} x_{1}+a_{M 2} x_{2}=M
\end{aligned}
$$

where $a_{i j}$ is the quantity of input $i$ used in producing the $\underline{j}^{\text {th }}$ good.

By substituting (3) into (1) and (2) we get:

$$
\begin{array}{ll}
\mathrm{R}_{\mathrm{L} 1} \mathrm{x}_{1}+\mathrm{R}_{\mathrm{L} 2} \mathrm{x}_{2} & =\mathrm{L} \\
\mathrm{R}_{\mathrm{K} 1} \mathrm{X}_{1}+\mathrm{R}_{\mathrm{K} 2} \mathrm{X}_{2} & =\mathrm{K}
\end{array}
$$

where $R_{i j}$ is the amount of the $i^{\text {th }}$ primary factor required directly or indirect ly for producing one unit of the $f^{\text {th }}$ final good. For example, $R_{L 1}=a_{L 1}+a_{L M} a_{M 1}$.

\section{The Price Equations}

Output prices are related to input prices by

$$
\begin{aligned}
a_{L 1} w+a_{K 1} r(1+t)+a_{M 1} p_{M} & =p_{1} \\
a_{L 2} w+a_{K 2} r & +a_{M 2} p_{M}=p_{2} \\
a_{L M} w+a_{K M} r & =P_{M}
\end{aligned}
$$

or, equivalently, by

$$
\begin{aligned}
R_{L 1} w+R_{K 1} r & +a_{K 1} r t & =p_{1} \\
R_{L 2} w+R_{K 2} r & & =P_{2}
\end{aligned}
$$

\section{Input-Output Coefficients}

These coefficients depend on factor prices, taking into account the tax in industry 1 . 


$$
\begin{aligned}
& a_{i 1}=a_{i 1}\left(w, r(1+t), P_{M}\right) \\
& a_{12}=a_{i 2}\left(w, r, P_{M}\right) \\
& a_{i M}=a_{i M}(w, r)
\end{aligned}
$$

The net or apparent capital-labor ratio in $j\left(R_{j}^{\prime}\right)$ is $K_{j}^{\prime} / L_{j}^{\prime}$, but the gross ratio $\left(R_{j}\right)$ is $R_{K j} / R_{L j}$.

\section{The Structure of Production}

Differentiation of equations (4) and (5) yields the following structural relations:

$$
\begin{aligned}
& \lambda_{\mathrm{L} 1} \mathrm{x}_{1}^{*}+\lambda_{\mathrm{L} 2} \mathrm{x}_{2}^{*}=\mathrm{L}^{*}-\left(\lambda_{\mathrm{I} 1} \mathrm{R}_{\mathrm{L} 1}^{*}+\lambda_{\mathrm{L} 2} \mathrm{R}_{\mathrm{L} 22}^{*}\right) \\
& \lambda_{\mathrm{K} 1} \mathrm{x}_{1}^{*}+\lambda_{\mathrm{K} 2} \mathrm{x}_{2}^{*}=\mathrm{K}^{*}-\left(\lambda_{\mathrm{K} 1} \mathrm{R}_{\mathrm{K} 1}^{*}+\lambda_{\mathrm{K} 2} \mathrm{R}_{\mathrm{K} 2}^{*}\right)
\end{aligned}
$$

where $\lambda_{i j}$ is the proportion of gross amount of $i^{\text {th }}$ primary factor used in the production of $\mathrm{j}^{\text {th }}$ final good, and asterisks denote proportional changes. From equations (6) to (13) we get:

$$
\begin{aligned}
\rho_{\mathrm{L} 1} \mathrm{w}^{*}+\rho_{\mathrm{K} 1}\left(\mathrm{r}^{*}+\mathrm{T}^{*}\right)+\rho_{\mathrm{M} 1} \mathrm{~B}_{\mathrm{M}}^{*} & =\mathrm{p}_{1}^{*} \\
\rho_{\mathrm{I} 2} \mathrm{w}^{*}+\rho_{\mathrm{K} 2} \mathrm{r}^{*}+\rho_{\mathrm{M} T} \mathrm{P}_{\mathrm{M}}^{*} & =\mathrm{p}_{2}^{*} \\
\rho_{\mathrm{IM}} \mathrm{w}^{*}+\rho_{\mathrm{KM}} \mathrm{r}^{*} & =\mathrm{P}_{\mathrm{M}}^{*}
\end{aligned}
$$

where $\rho_{i j}$ is the share of the $i^{\text {th }}$ factor in the $j^{\text {th }}$ industry (share of capital in $X_{1}$ is gross of $\left.t a x\right)$, and $T^{*}=(1+t)^{*}$. By substituting (18) into (16) and (17) we can write:

$$
\begin{aligned}
& \theta_{\mathrm{L} 1} w^{*}+\theta_{\mathrm{K} 1} \mathrm{r}^{*}+\rho_{\mathrm{K} 1} \mathrm{~T}^{*}=\mathrm{p}_{1}^{*} \\
& \theta_{\mathrm{I} 2} w^{*}+\theta_{\mathrm{K} 2} \mathrm{r}^{*}=\mathrm{p}_{2}^{*}
\end{aligned}
$$

where $\theta^{\prime}$ s are gross factor shares, e.g., $\theta_{\mathrm{L} 1}=\rho_{\mathrm{L} 1}+\rho_{\mathrm{M} 1} \rho_{\mathrm{IM}}, \theta_{\mathrm{K} 2}=\rho_{\mathrm{K} 2}+\rho_{\mathrm{M} 2} \rho_{\mathrm{KM}}$, 
etc. Let $|\lambda|$ denote the determinant of the matrix of $\lambda$ coefficients in (14) and (15), and let $|\theta|$ be the determinant of the factor-shares matrix in (19) and (20). The signs of $|\lambda|$ and $|\theta|$ depend on factor intensities. If $K_{1} / K_{2}>I_{1} / I_{2},|\lambda|>0$, and $|\theta|$ will be positive whenever $\theta_{K 1}>\theta_{K 2}$. It is well known in the literature on factor-market distortions (e.g., Jones (1971a)) that when a tax like CIT is present, the rank of industries in physical terms can be different from the rank in value terms, i.e., $|\lambda|$ and $|\theta|$ can have opposite signs.

\section{The Demand Equation}

For simplicity it is assumed that the government spends the tax revenue exactly as private individuals do, that income distribution does not affect demand, and that all individuals have identical tastes. These assumptions, together with the stipulation of full employment, imply that there is only one independent demand equation which can be written as:

$$
x_{1}=f\left(p_{1} / p_{2}, Y\right)
$$

where $\mathrm{Y}$ is total income in the economy. Private disposable income is $w \mathrm{~L}+\mathrm{rK}$ and government's income (revenue) equals $\mathrm{rtK}_{1}^{\prime}$. By totally differentiating (21) and separating the income and substitution effect terms, we get:

$$
x_{1}^{*}=\epsilon\left(p_{1}^{*}-p_{2}^{*}\right)+\frac{m}{x_{1}}\left(d Y-x_{1} d p_{1}-x_{2} d p_{2}\right)
$$

where $\epsilon$ is the income compensated elasticity of demand and $m$ is the marginal propensity to consume $x_{1} \cdot 3$

The Solution

The solution essentially requires equating the proportlonate change in supply of $x_{1}$ to the corresponding change in its demand, after taking into account the full employment conditions and the price equations. Some of these equations can be simplified by choosing the wage rate as the numeraire in terms of which all other prices are expressed ( ${ }^{*}$ thus is equal 
to zero everywhere), by setting $p_{1}=1$ by a suitable choice of units, and by invoking the assumption of fixed factor endowments so that $L^{*}=K^{*}=0$ in (14) and (15).

To deal with questions of incidence, the model has to be solved for $r^{*}$ or $\mathrm{r}^{*} / \mathrm{T}^{*}$, the elasticity of return to capital with respect to the tax rate. Since $w$ is the numeraire, $r$ is the relative price of capital. If $r^{*}$ turns out to be zero, labor and capital will bear the tax in proportion to their initial shares in national income. Capital's relative tax burden will be greater than in this situation if $r^{*}<0$, and the opposite result will hold if $\mathrm{r}^{*}>0$.

By using (19) and (20), equation (22) leads to (23) (see the Appendix for details):

$$
\mathrm{x}_{1}^{*}=\epsilon\left(\mathrm{p}_{1}^{*}-\mathrm{p}_{2}^{*}\right)+\frac{\mathrm{m}}{\mathrm{x}_{1}} \times \mathrm{t} \mathrm{K}_{1}^{\prime} \mathrm{K}_{1}^{\prime *}
$$

where $K_{1}^{\prime}\left(a_{\mathrm{K} 1} x_{1}\right)$ is capital directly used in producing $x_{1} \cdot$

Applying Cramer's rule to (14) and (15) we get:

$$
\mathrm{x}_{1}^{*}=\frac{\lambda_{\mathrm{L} 2} \lambda_{\mathrm{K} 1} \mathrm{R}_{\mathrm{K} 1}^{*}-\lambda_{\mathrm{K} 2} \lambda_{\mathrm{L} 1} \mathrm{R}_{\mathrm{L} 1}^{*}+\lambda_{\mathrm{L} 2} \lambda_{\mathrm{K} 2} \mathrm{R}_{\mathrm{K} 2}^{*}-\lambda_{\mathrm{K} 2} \lambda_{\mathrm{L} 2} \mathrm{R}_{\mathrm{L} 2}^{*}}{\lambda_{\mathrm{L} 1} \lambda_{\mathrm{K} 2}-\lambda_{\mathrm{K} 1} \lambda_{\mathrm{L} 2}} \text {. }
$$

For further simplification, we need solutions for $R^{*}, s$ and $a_{K 1}^{*}$ (because in equation (23) $k_{1}^{*}=a_{K 1}^{*}+x_{1}^{*}$ ). These solutions, derived in the Appendix, are as follows:

$$
\begin{aligned}
& R_{L 1}^{*}=\frac{\alpha+\xi}{\theta_{L 1}} \mathbf{r}^{*}+\frac{\rho_{L 1} \rho_{\mathrm{K} 1} \sigma_{\mathrm{LK}}^{1}+\rho_{\mathrm{LM}} \rho_{\mathrm{M} 1} \rho_{\mathrm{K} 1} \sigma_{\mathrm{KM}}^{1}}{\theta_{L 1}} \mathbf{T}^{*} \\
& \mathrm{R}_{\mathrm{K} 1}^{*}=-\frac{\alpha+E}{\theta_{\mathrm{K} 1}} \mathrm{r}^{*}-\frac{\rho_{\mathrm{L} 1} \rho_{\mathrm{K} 1} \sigma_{\mathrm{LK}}^{1}+\rho_{\mathrm{LM}} \rho_{\mathrm{M}} \sigma_{\mathrm{KM}}^{1}}{\theta_{\mathrm{K} 1}} \mathrm{~T}^{*} \\
& R_{L 2}^{*}=\frac{\beta+\delta}{\theta_{L 2}} r^{*} \text {, and } R_{K 2}^{*}=-\frac{\beta+\delta}{\theta_{K 2}} r * \\
& a_{\mathrm{K} 1}^{*}=-\left(\rho_{L 1} \sigma_{I K}^{1}+\rho_{M I} \rho_{L M} \sigma_{K M}^{1}\right) r^{*}+\left(\rho_{L 1} \sigma_{L K}^{1}+\rho_{M 1} \sigma_{K M}^{1}\right) T^{*}
\end{aligned}
$$


Here

$$
\begin{aligned}
& \alpha=\rho_{L 1} \rho_{K 1} \sigma_{I K}^{1}+\rho_{K M}^{2} \rho_{L 1} \rho_{M 1} \sigma_{I M}^{1}+\rho_{L M}^{2} \rho_{K 1} \rho_{M 1} \sigma_{K M}^{1} \\
& \beta=\rho_{L 2} \rho_{K 2} \sigma_{L K}^{2}+\rho_{K M}^{2} \rho_{L 2} \rho_{M 2} \sigma_{I M}^{2}+\rho_{L M}^{2} \rho_{K 2} \rho_{M 2} \sigma_{K M}^{2} \\
& \xi=\rho_{L M} \rho_{K M} \rho_{M 1} \sigma_{I K}^{M}, \text { and } \delta=\rho_{I M} \rho_{K M} \rho_{M 2} \sigma_{I K}^{M}
\end{aligned}
$$

The elasticity of substitution between labor and capital in $M, \sigma_{I K}^{M}$ is $\left(a_{\mathrm{KM}}^{*}-a_{\mathrm{LM}}^{*}\right) /\left(w^{*}-r^{*}\right)$ which is positive. Other $\sigma^{\prime} s$ denote partial elasticities of substitution in $X_{1}$ and $x_{2}$ as defined by Allen (1969). These can be negative (complementary factors) or positive (substitutes). However, for a linear, homogeneous production function with three inputs, a sufficient condition for stability of the derived demand for inputs is $\rho_{\mathrm{KI}} \sigma_{\mathrm{KK}}^{1}+\rho_{\mathrm{LI}} \sigma_{\mathrm{LK}}^{1}+$ $\rho_{M i} \sigma_{K M}^{1}=0$ (Allen, p. 504) which implies that an equi-proportionate change in all input prices will not alter techniques. Each 'own' elasticity must be negative, so either all 'cross' elasticities are positive--which makes $\alpha$ and $\beta$ positive--or at most one of the $\sigma^{\prime} s$ is negative. Although in this case as well $\alpha$ and $\beta$ will be positive, ${ }^{5}$ the possibility of complementarity between some factors is a unique feature of production functions with more than two inputs, and as we shall see in section III, it complicates tax-incidence analysis. If there are only two factors of production, for instance in industry $M$, they must be substitutes and the corresponding $\sigma$ will be positive. Another implication of the above stability condition is that if one of the cross-elasticities is zero--say $\sigma_{\mathrm{KM}}^{i}-$ the other, $\sigma_{\mathrm{LK}}^{1}$, must be positive. This result also will be useful in Section III.

Substituting the expressions for $\mathrm{R} *$ 's and $a_{\mathrm{K} 1}^{*}$ into (23) yields: 
$\mathrm{x}_{1}^{*}=\frac{\left\{\varepsilon\left(\theta_{\mathrm{K} 1}-\theta_{\mathrm{K} 2}\right) \mathrm{r}^{*}+\varepsilon \rho_{\mathrm{KI}} \mathrm{T}^{*}-\mathrm{c}\left[\left(\rho_{\mathrm{L} 1} \sigma_{\mathrm{LK}}^{1}+\rho_{\mathrm{M} 1} \sigma_{\mathrm{KM}}^{\top}\right) \mathrm{T}^{*}+\left(\rho_{\mathrm{M} 1} \rho_{\mathrm{LM}} \sigma_{\mathrm{KM}}^{1}+\rho_{\mathrm{LI}} \sigma_{\mathrm{LK}}^{1}\right) \mathrm{r}^{*}\right]\right\}}{(1-\mathrm{C})}$

where $C=m \frac{t}{1+t} \rho_{\mathrm{K} 1}$. Similarly, we obtain from (24):

$$
\mathrm{x}_{1}^{*}=\begin{aligned}
& {\left[\left\{\left(\theta_{\mathrm{K} 1} \frac{\mathrm{L}_{1}}{\mathrm{~L}_{2}}+\theta_{\mathrm{L} 1} \frac{\mathrm{K}_{1}}{\mathrm{~K}_{2}}\right)\left(\rho_{\mathrm{L} 1} \rho_{\mathrm{K} 1} \sigma_{\mathrm{LK}}^{1}+\rho_{\mathrm{K} 1} \rho_{\mathrm{M} 1} \rho_{\mathrm{LM}} \sigma_{\mathrm{KM}}^{1}\right) / \theta_{\mathrm{L} 1} \theta_{\mathrm{K} 1}\right\} \mathrm{T}^{*}\right.} \\
& \left.+\left\{\frac{\alpha+\xi}{\theta_{\mathrm{L} 1} \theta_{\mathrm{K} 1}}\left(\theta_{\mathrm{K} 1} \frac{\mathrm{L} 1}{\mathrm{~L} 2}+\theta_{\mathrm{L} 1} \frac{\mathrm{K}_{1}}{\mathrm{~K}_{2}}\right)+\frac{\beta+\delta}{\theta_{\mathrm{L} 2} \theta_{\mathrm{K} 2}}\right\} \mathrm{r}^{*}\right] /\left(\frac{\mathrm{K}_{1}}{\mathrm{~K}_{2}}-\frac{\mathrm{I}_{1}}{\mathrm{~L}_{2}}\right)
\end{aligned}
$$

The basic incidence equation (27) is derived by setting the demand side (25) equel to the supply side (26) and solving for $r^{*}$ :

$$
r^{*}=\frac{\epsilon \rho_{K 1} A-A C\left(\rho_{L 1} \sigma_{L K}^{1}+\rho_{M I} \sigma_{K M}^{1}\right)-B(1-C) D}{\epsilon\left(\theta_{K 2}-\theta_{K 1}\right) A+B G+F-C(B G+F-A H)} \cdot T^{*} \text {. }
$$

where $A=\frac{K_{1}}{K_{2}}-\frac{I_{1}}{I_{2}}, \quad B=\theta_{K 1} \frac{I_{1}}{I_{2}}+\theta_{L 1} \frac{K_{1}}{K_{2}}, C$ as defined above $=m \frac{t}{1+t} \rho_{K 1}$,

$$
\begin{aligned}
& D=\left(\rho_{\mathrm{K} 1} \rho_{L 1} \sigma_{L K}^{1}+\rho_{L M} \rho_{M 1} \rho_{K 1} \sigma_{K M}^{1}\right) / \theta_{L 1} \theta_{K 1}, \quad F=(\beta+\delta) / \theta_{K 2} \theta_{L 2} \\
& G=(\alpha+\xi) / \theta_{K 1} \theta_{L 1} \text {, and } H=\left(\rho_{M 1} \rho_{I M} \sigma_{K M}^{1}+\rho_{L 1} \sigma_{L K}^{1}\right) .
\end{aligned}
$$

A11 these terms w111 be positive except $D$ and $H$ which can be negative if $\sigma_{\mathrm{KM}}^{I}$ or $\sigma_{\text {IK }}^{1}<0$.

Intermediate goods affect almost every term in the expression for $r *$ Capital and labor used in producing $M$ are reflected in factor intensities and factor shares ( $R$ 's and $\theta$ 's) in $X_{1}$ and $X_{2}$. Elasticity of substitution between $K$ and $M$ appears directly in the numerator of (27) while other elasticities involving the intermediate good show up indirectly, as components of $\mathrm{F}$, $\mathrm{G}$, and $\mathrm{H}$. It is easy to verify that if there are no intermediate goods, equation (27) reduces to the solution reported by Ballentine and Eris (1975) (their equation (3)), and if, in addition, there are no initial taxes, it boils down to Harberger's general result (his equation (12)) although the equations and notation used by these authors differ slightly from ours. 


\section{IMPLICATIONS FOR TAX-INCIDENCE}

Answers to questions of tax incidence in the present model depend crucially on whether $r^{*} \gtrless 0$. Before exploring this point further, let us establish two propositions--one about gross and net factor intengities, and the other about the sign of the denominator of (27).

Factor intensities. - There is no necessary correspondence between gross and net factor intensities. Gross capital-labor ratio $\left(K_{i} / L_{i}\right)$ in industry $\underline{i}$ is defined as $R_{K i} / R_{L i}$ whereas the net ratio $\left(K_{i}^{\prime} / L_{i}^{\prime}\right)$ is given by $a_{K i} / a_{L i}$. Since $R_{K i} / R_{L i}=\left(a_{K i}+a_{M i} a_{K M}\right) /\left(a_{L i}+a_{M i} a_{L M}\right)$, it is possible that $\left(K_{1} / L_{1}\right)>\left(K_{2} / L_{2}\right)$ even if $\left(K_{1}^{\prime} / L_{1}^{\prime}\right)<\left(K_{2}^{\prime} / L_{2}^{\prime}\right)$, for example, if the intermediate good has a high capital labor ratio and it is used mostly in the first industry.

The sign of the denominator of $(27)(\Delta)$. - In (27), B, G, F, and C, are positive by definition, but the sign of $A$ depends on relative factor intensities and $\mathrm{H}$ can be negative. Therefore, in general, nothing definite can be said about $\Delta$ except that it will be positive if $A=0$, 1.e,, gross factor intensities in the two final goods industries are equal because $c<1$. 6 However, in a wide range of situations likely to be empirically relevant for the U.S. economy, $\Delta$ will be positive. ${ }^{7}$

Therefore, in the following discussion it is assumed that the sign of $r *$ depends only on the numerator of (27). Analytical considerations are enough to justify this assumption in many cases; in other cases we invoke the empirical results cited here. 
Some General Results

1. The greater are the elasticities of substitution between labor and capital in the untaxed industries, the more likely it is that capital and labor will bear the tax burden in proportion to their initial contribution to national income. These elasticities determine how easily the untaxed industries will absorb the capital and labor ejected from the corporate sector in response to the corporation income tax. Both $\sigma_{L K}^{2}$ and $\sigma_{L K}^{M}$ occur only in the denominator of (27), as components of $\beta$ and $\delta$ respectively. In the limit, when either of these elasticities approaches infinity, $r$ goes to zero, relative factor prices do not change, hence capital and labor bear the tax burden in proportion to their initial factor shares.

2. When the elasticity of demand for the taxed commodity is zero, and $\sigma_{\mathrm{KM}}^{1}=0$, capital's share of the tax burden will be greater than its initial contribution to national income as long as the corporate sector is not relatively labor. intensive.

The stability condition discussed in the preceding section ensures that when $\sigma_{K M}^{1}=0, \sigma_{L K}^{1}$ will be positive. With $\epsilon=0$, only two terms remain in the numerator of (27). The second, $-\mathrm{B}(1-C) \rho_{\mathrm{KL}} \rho_{\mathrm{LI}} \sigma_{\mathrm{LK}}^{1}$, is negative, and the first will also be negative so long as $A>0$ and $\sigma_{I K}^{1}, \sigma_{\mathrm{KM}}^{1} \geq 0$.

If $K$ and $M$ are complements in $X_{1}$, the two terms in the numerator of (27) can be positive (although $\sigma_{L K}^{1}$ will still be positive). Depending on empirical magnitudes of $\rho^{\prime} s$ and $\sigma^{\prime} s$, therefore, $r *$ can be positive. A similar argument applies when $\sigma_{I K}^{1}<0$.

3. Labor's share of the tax burden can be higher than its share

in national income only if the taxed industry is more labor intensive (in the gross sense) than the untaxed industry when there are no complementary inputs. For this result to hold, $r^{*}$ has to be positive. If 
all $\sigma^{\prime}$ s are non-negative, the only terms which can make the numerator of (27) positive are $\epsilon \rho_{K 1} A-A C\left(\rho_{I 1} \sigma_{I K}^{1}+\rho_{M} \sigma_{K M}^{1}\right)$ when $A<0$, 1.e. $I_{1} / I_{2}>K_{1} / K_{2}$. In the Harberger model this result is true if the net capital-labor ratio is lower in $X_{1}$ than in $X_{2}$, i.e., if $I_{1}^{\prime} / I_{2}^{\prime}>K_{1}^{\prime} / K_{2}^{\prime}$. This condition may no longer be sufficient because, as discussed at the outset in this section, net factor intensities will not necessarily correspond with gross factor intensities. Moreover, some of the $\sigma^{\prime} s$ can be negative, so $r^{*}$ can be negative even if $A<0$.

4. When all factors are used in fixed proportions throughout the economy, the incidence of tax depends solely on gross factor shares in $X_{1}$ and $x_{2}$. In this case, (27) simplifies to $\mathrm{r}^{*}=\mathrm{T}^{* \rho_{\mathrm{K} 1}} /\left(\theta_{\mathrm{K} 2}-\theta_{\mathrm{K} 1}\right)$ which is positive when $\mathrm{x}_{2}$ is more capital intensive than $\mathrm{X}_{1}$ and vice versa. This is Harberger's conclusion no. 8, restated here in terms of gross factor intensities, and his explanation holds exactly: If all $\sigma^{\prime} s$ are zero, and factor proportions in the two industries are different, full employment can be ensured by only one set of outputs for $x_{1}$ and $x_{2}$, and demand conditions then require that relative output prices do not change. Since output of the two final goods does not change, the relative price of capital must fall if $x_{1}$ is relatively capital intensive and vice versa.

\section{When factor proportions in the two fingl-good industries are} the same, demand considerations have no bearing on questions of tax incidence. When $A=0$, all terms involving $\epsilon$ and $m$ drop out and $r^{*}=-B D /(B G+F)$. Household demands still affect the mix of final outputs produced but this has no effect on the derived demand for factors and factor prices. Tax burden, therefore, will depend only on factor shares and various elasticities of substitution throughout the economy. 
6. When factor proportions in the two final-good industries are the same, an increase in CIT will burden capital more than its income share so long as $K$ and $L$, and $K$ and $M$ are not complementary to each other in the corporate sector.

In this case $r^{*}=-B D /(B G+F)$ which must be negative whenever $\sigma_{L K}^{1}$ and $\sigma_{\mathrm{KM}}^{1}$ are positive. If one of these $\sigma^{\prime} \mathrm{s}$ is zero, the other must be positive (because of the stability condition), so ${ }^{*}$ will still be negative.

\section{Comparison with Harberger's General Results}

Since the theoretical framework used here is an extension of the Harberger model which has only final goods, it is natural to ask how the above results compare with Harberger's general conclusions. Because of intermediate goods, it is obvious that gross rather than net factor intensities are relevant here. Equally important is the fact that the elasticities of substitution in the final goods industries here are partial elasticities which have different definitions and economic meaning than in the two-factor case. For instance, $\sigma_{\mathrm{LK}}^{1}$ in this model records the effect of changing the wage rate on $k_{1}$ holding output and other input prices constant. Although an analogous definition can be given for the two-factor model (Jones (1971b)), the well-known implications of $\sigma_{L K}^{1}$ in that case for output shares and input ratios do not carry over to the three-input model. 8

Keeping these points in view, our results 1, 3, and 4 are mutatis mutandis restatements of Harberger's propositions 1, 4, and 8 respectively, incorporating gross factor intensities and additional elasticities of substitution. Result 5, derived above, will also hold in the Harberger model but $K_{1}^{\prime} / L_{1}^{\prime}=K_{2}^{\prime} / L_{2}^{\prime}$, will not suffice in our model; gross capital-labor ratios will have to be equal for $A$ to vanish. 
There is nothing comparable to our results 2 and 6 in the Harberger model because it cannot have complementary factors, and whenever demand is inelastic, all terms involving $A$ disappear. In this model, even when $\epsilon=0$, capital-labor ratios in the two industries continue to affect $r$.

A number of analytical results derived by Harberger will not be generally valid in the present model. For example, in the Harberger specification, if $\left|\sigma_{I R}^{1}\right| \geq|\epsilon|$, capital must bear the tax more than in proportion to its initial income share. This result holds a fortiori when $\left|\sigma_{L K}^{1}\right| \geq\left|\sigma_{D}\right|$, (Harberger's propositions 2 and 3). When intermediate goods are present, these conditions are neither necessary nor sufficient for that result. The only term which can make the numerator of (27) positive, as in the Harberger formulation, is $-\omega_{\mathrm{K} 1} \mathrm{~L}_{1} / \mathrm{L}_{2}$ but unlike the Harberger case, it is not clearly dominated by any other term even if $\left|\sigma_{L K}^{1}\right| \geq|\epsilon|$. There are other negative terms in the numerator of (27), so there is a good possibility that the Harberger results will hold even if these cannot be proved analytically. Harberger's conclusion number 5 also cannot be proved because $\sigma_{L K}^{1}$ does not appear in the numerator and denominator of (27) with equal coefficients. Again, in the Harberger model, when factor proportions are initially the same in the two industries, tax burden depends solely on the two elasticities of substitution between labor and capital (proposition 6). In the present case, when $A=0, r^{*}=-B D /(B G+F)$, so $\underline{a 11}$ elasticities of substitution and factor shares affect $r *$ and any result is possible. The empirical results in the next section and the simulations that follow will shed more light on these propositions which can no longer be sustained on analytical grounds alone. 


\section{EMPIRICAL ESTIMATES}

Some empirical results for the U.S. economy for the years 1953-55 were presented by Harberger $(1959,1962)$ and modified for finite taxes by Ballentine and Eris (1975). In this section we wish to determine how intermediate goods alter these results. The computations are illustrative and not definitive because no direct information on intermediate goods during this period is available. The nearest input-output table is for 1958 and it does not use all the same industry classifications as in the Harberger analysis, nor is any distinction made between corporate and non-corporate sectors. Therefore we are forced to make a series of approximations. 9

It is assumed first that the 1958 coefficients apply to $1953-55$ as weIl, and that intermediate good $(M)$ is provided by "farms" and "agricultural services, forestry, fisheries" in Harberger's classification. The input-output data show that about 23 per cent of agricultural output was used as final goods. The intermediate good's contribution to national income thus is estimated at $0.77 \times \$ 16$ bilition, the figure reported for farms by Harberger (1959) +0.8 billion, the corresponding number for agricultural services, etc. Income of labor and capital in $M$ is similarly calculated. Next, we assume that output of $M$ is divided equally between $X_{7}$ and $x_{2}$, so half of $w I_{M}$ and $r K_{M}$ are added to factor incomes in $X_{1}$ and $X_{2}$. With these adjustments, we heve, in billions of dollars, $r K_{1}=22.0, r t K_{1}^{\prime}=20, w I_{1}=205.0$, $r K_{2}=18.2$, and $w L_{2}=15.7$. Recall that $K_{i}$ and $L_{i}$ are "total" capital and labor used in industry $\underline{i}$. Besides these we have $\rho_{\mathrm{K} 1}=.16, \rho_{\mathrm{L} 1}=.81$, $\rho_{\mathrm{K} 2}=0.48, \rho_{\mathrm{L} 2}=0.30$, and $\rho_{\mathrm{KM}}=0.29$. With these numbers every term in (27) except those involving $\sigma_{1 j}$ 's and $\epsilon$ can be calculated. In Table 1 we consider various values for $\sigma^{\prime} s$ and $\sigma_{D}$, the elasticity of substitution in demand, from which 6 is computed. 11 
It is clear from Table 1 that $r^{*}$ can vary over a fairly wide range, from .12 to -.71 . In the Harberger model, when all elasticities of substitution are unity, $\mathrm{r}^{*}=-.50,-.57$, and -.44 , as $\sigma_{\mathrm{D}}=-1,-0.5$, and -1.5 respectively (Ballentine and Eris (1975), p. 641). Comparable cases here will be rows 1 or 2 in Table 1 because one might be justified in ignoring intermediate goods if they have to be used in fixed proportions, i.e., if they cannot be substituted for labor or capital in producing the final goods. ${ }^{12}$ Values of $r^{*}$ thus will be higher by 8 to 17 per cent in absolute terms depending on the assumptions made for $\sigma_{D}$ and $\sigma_{L K^{*}}^{M}$ Ballentine and Eris (1975) suggested that Harberger, by omitting net-income terms associated with an existing finite tax, overestimated $r^{*}$ by $16-20$ per cent. Our results show that ignoring intermediate goods leads to an underestimate. The correct value of $\mathrm{r}^{*}$ seems to lie somewhere in the middle of the range of values computed from models with only final goods. It is exactly at the half-way mark if $\sigma_{D}=-1$. Several other features of the results in Table 1 also deserve to be emphasized:

1. The elesticity of substitution between the two final goods has a sizable effect on the magnitude of $r^{*}$, as much as 40 per cent in some cases. In general, higher values of $\sigma_{D}$ are favorable to capital: as $\sigma_{D}$ increases, tax burden on capital decreases.

2. The smaller is the elasticity of substitution between labor and capital in the taxed industry, other things being equal, the lower is the burden of tax on capital. When $\sigma_{\mathrm{IK}}^{1}=0.66, \mathrm{r}^{*}$ goes down from $-.51\left(\sigma_{\mathrm{KI}}^{1}=1\right)$ to -.40 , and when $\sigma_{\mathrm{KL}}^{1}=0.001, \mathrm{r}^{*}=0.12$.

3. As possibilities of substituting labor for capital, directly or indirectly, in the untaxed industries decrease, capital has to absorb a higher portion of the tax. In the extreme case, with $\sigma_{L K}^{2}=\sigma_{K M}^{2}=\sigma_{L M}^{2}=\sigma_{L K}^{M}=0.001, r^{*}=-.71$, almost 40 per cent more than the situation in which all $\sigma^{\prime} \mathrm{s}$ equal unity. 
TABLE 1

\section{Elasticity of Net-of-Tax Return to Capital}

with Respect to Tax Rate $\left(r^{*} / T^{*}\right)^{a}$

(1) $\sigma_{L K}^{1}=\sigma_{L K}^{2}=\sigma_{L K}^{M}=1$, other $\sigma^{\prime} s=0.001$

$$
\begin{array}{cccc}
\frac{\sigma_{D}=-1}{-.54} & \frac{\sigma_{D}=-0.5}{-.62} & \frac{\sigma_{D}=-1.5}{-.47} & \frac{\varepsilon=0}{-.72} \\
-.58 & -.67 & -.50 & -.78
\end{array}
$$

(2) $\sigma_{L K}^{1}=\sigma_{L K}^{2}=1$, other $\sigma^{\prime} s=0.001$

(3) $\sigma_{\mathrm{LK}}^{1}=\sigma_{\mathrm{KM}}^{1}=\sigma_{\mathrm{LM}}^{1}=0 ; 001$, other $\sigma^{\prime} \mathrm{s}=1$

.15

.09

.19

0.0

(4) $\sigma_{\mathrm{IM}}^{2}=\sigma_{\mathrm{KM}}^{2}=\sigma_{\mathrm{LK}}^{2}=0.001$, other $\sigma^{\prime} \mathrm{s}=1$

$-.64$

$-.75$

$-.55$

$-.88$

(5) $\sigma_{I M}^{1}=\sigma_{K M}^{1}=\sigma_{L K}^{1}=1$, other $\sigma^{\prime} s=0.001$

$-.71$

$-.83$

$-.60$

$-.99$

(๘) $\sigma_{\mathrm{KM}}^{1}=\sigma_{\mathrm{KM}}^{2}=\sigma_{\mathrm{LK}}^{\mathrm{M}}=0.001$, other $\sigma^{\prime} \mathrm{s}=1$

$-.57$

$-.66$

$-.50$

$-.77$

(7) $\sigma_{L K}^{1}=0.66$, other $\sigma^{\prime} s=1$

$-.40$

$-.48$

$-.33$

$-.59$

(8) All $\sigma^{\prime} \mathrm{s}=0.66$

$-.45$

$-.54$

$-.37$

$-.67$

(9) All $\sigma^{\prime} s=1$

$-.51$

$-.58$

$-. .45$

$-.67$

at is assumed that the intermediate good is divided equally between the two final products. 
4. When the elasticity of demand for the taxed commodity is zero, owners of capital invariably suffer more than in other situations. In column 4 of Table 1, ${ }^{*}$ always has higher negative values than in any of the other columns, and even the positive values in the third row are replaced by zero.

There is nothing surprising about these conclusions. As the tax on corporate capital is increased, attempts are made to avold the tax burden by increasing the relative output of the untaxed final good, and by substituting labor for capital throughout the economy. Points 1,3 , and 4 have a direct bearing on such attempts, and the second point determines how much capital and labor per unit of output will be released as the corporate sector contracts in response to a tax increase.

\section{Effects of Separability and Fixed Proportions}

It has often been assumed that primary factors are separable from intermediate goods in the production process, and that such goods are used in fixed proportions (by Fullerton, Shoven, and Whalley (1978) for example). A necessary and sufficient condition for such separability, according to Blackorby and Russel1 (1976), is that $\sigma_{\mathrm{KM}}^{1}=\sigma_{\mathrm{LM}}^{i}$. This condition is satisfied in several rows in Table 1 but the additional restriction of fixed proportions between the primary factors and $M$ in both $x_{1}$ and $x_{2}$ is met only in row 1 . Estimates of $r^{*}$ there are higher than those in row 9 by about 6 percent. Simulation results in Table 3 indicate that if the intermediate good has a larger share $(2 / 3)$ in the noncorporate sector, these assumptions of separability and fixed proportions can make a difference of about 10 percent in calculating $r^{*}$.

\section{The Role of Complementarity}

It was noted earlier that one $\sigma_{i j}(i \neq j)$ could be negative in each final-good industry, which raises the possibility of complementary inputs. We have seen how a negative value for $\sigma_{\mathrm{KM}}^{1}$ or $\sigma_{\text {LK }}^{1}$ might reverse the sign of 
$r *$ In some of the general results reported above. With the data at hand, one can gauge the effects of complementarity on the magnitude of $r *$. It is not easy to find examples of complementary inputs of the type being used here. It is particularly hard to imagine a situation in which rental of capital goes up and less of labor is used, keeping output and other input prices constant, as a negative $\sigma_{L K}$ will require. In the following illustrations, therefore, we consider only cases of complementarity with M (although even these will not occur very frequently) using row 9 in Table 1 as a benchmark. If $K$ and $M$ are complements in $x_{1}\left(\sigma_{K M}^{1}=-1\right), r *$ in each column of row 9 goes down by about 2 percent. A negative $\sigma_{L M}^{1}$, however, raises these estimates by about 2 percent. If $\sigma_{\mathrm{KM}}^{2}$ is set equal to $-1, \mathrm{r} *$ equals $-.57,-.66$, -.50 , and -.76 as $\sigma_{D}$ is varied from -1 to 0 . When both $\sigma_{\mathrm{KM}}^{1}$ and $\sigma_{\mathrm{KM}}^{2}$ equal -1 , the corresponding values of $r *$ are $-.55,-.64,-.48$ and -.74 . On the other hand, when $\sigma_{I M}^{1}$ and $\sigma_{L M}^{2}$ are set equal to $-1, r^{*}$ drops to $-.53,-.61,-.46$, and -.70 . Finally, these estimates of $r *$ do not seem to be very sensitive to particular negative values of $\sigma_{\mathrm{KM}}$ and $\sigma_{\mathrm{LM}}$ : changing them from -1 to -0.5 alter these results but 1 ittle.

\section{SOME SENSITIVITY TESTS OF THE EMPIRICAL RESULTS}

The data used in deriving the results reported above were compiled by making a series of approximations and strong assumptions in some cases. It should be no surprise to find sizable errors, especially in variables pertaining to the intermediate good--the size of $M$ and its allocation between $X_{1}$ and $X_{2}$. In what follows, we vary the allocation of $M$ between $x_{1}$ and $x_{2}$, and increase the size of the intermediate good sector. 13

Two sets of results are set out in Table 2-one in which $X_{7}$ is assumed to use 90 per cent of the output of $M$, and the second in which this fraction is reduced to 5 per cent. In both cases, the numbers are within \pm 5 per cent 


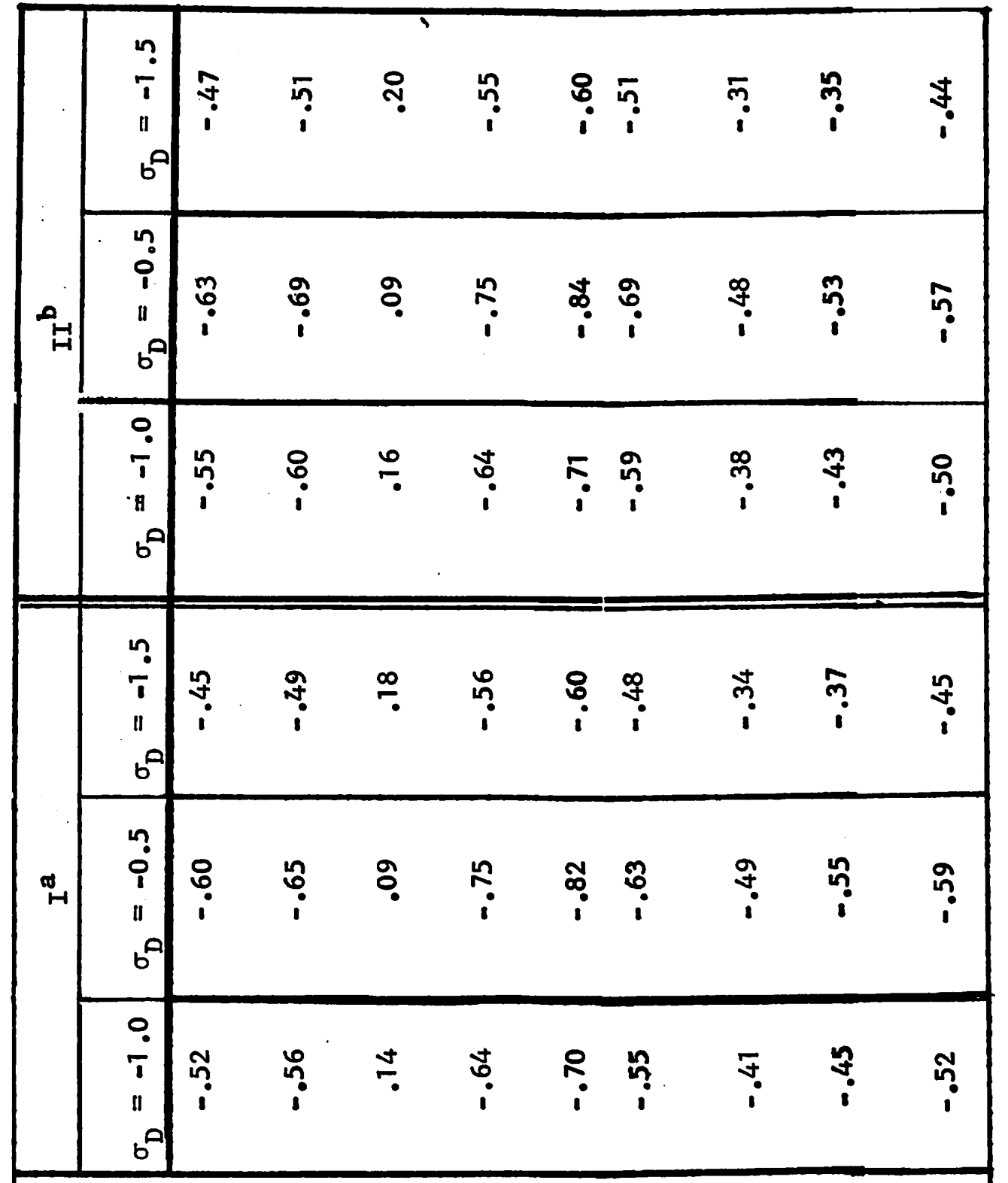

म

$\begin{array}{llllll}-1 & -1 & -1 & 0 & -1 \\ 0 & \ddot{0} & 0 & 0 & 0\end{array}$

$\begin{array}{llllll}\| & -1 & 0 & 0 & 0 & \overline{0} \\ \infty & 0 & 0 & 11 & \end{array}$

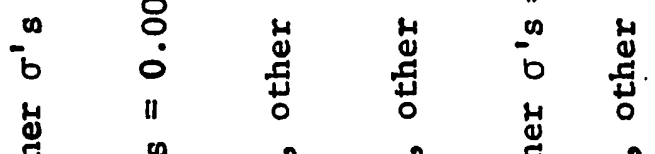

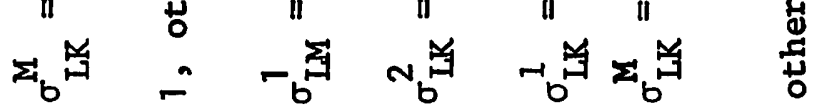

" II II $\|$ II

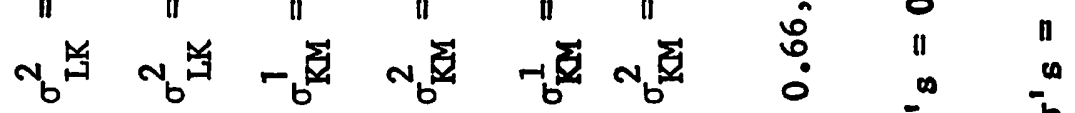

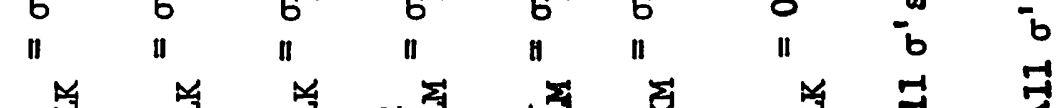

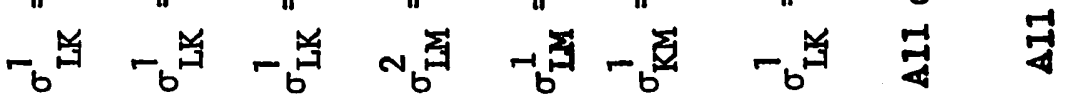

å

II

$\sum_{\infty}^{ \pm} \sum^{5}$

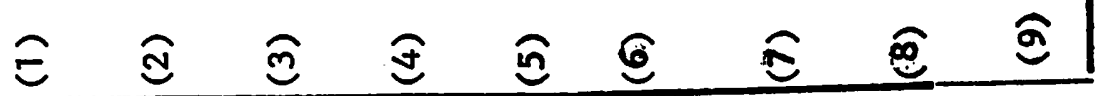


of those reported in Table 1. For the data at hand, therefore, any error in computing the share of $M$ used in each industry will not alter the estimates of $r^{*}$ very much.

These estimates, on the other hand, are more sensitive to the size of M. In Table 1, the intermediate good amounted to about a third of the noncorporate sector. In Table 3 we present comparable results for two other cases in which the relative size of $M$ is increased to a half and then twothirds of the output in the noncorporate sector. Under the first assumption, estimates of $r^{*}$ by and large stay close to those in Table 1 , exceeding the latter by about 4 percent in row 2 . It is a different story in the second case: $r *$ in row 2 exceeds the corresponding number in Table 1 by 20 percent In some instances. Results do not change much in other cases, and $r *$ is almost identical under the three assumptions when al1 $\sigma$ 's are equal (rows 8 and 9) or when no elasticity of substitution is zero (row 7).

\section{CONCLUSIONS}

We have demonstrated the wide range of results that can be derived when pure intermediate goods are introduced into a general. equilibrium model of the incidence of the corporation income tax in which a finite tax already exists. Several theoretical conclusions about the role of such goods are established. It is also shown that many well-known propositions about the incidence of the corporation income tax, emanating from models with only final goods, need to be modified. Bmpirical results, derived from U.S. data for 1953-55 used by Harberger as weII, suggest that the elasticity of capital's rate of return with respect to the tax rate has been underestimated by 8 to 17 per cent due to the exclusion of intermediate goods. Simulations further indicate that these results can depart even more from those in models with only final goods if intermediate goods are a relatively large sector in the economy and there are rather limited possibilities of substituting capital for labor in their production, and of substituting them for other productive factors in the final-good industries. 14 


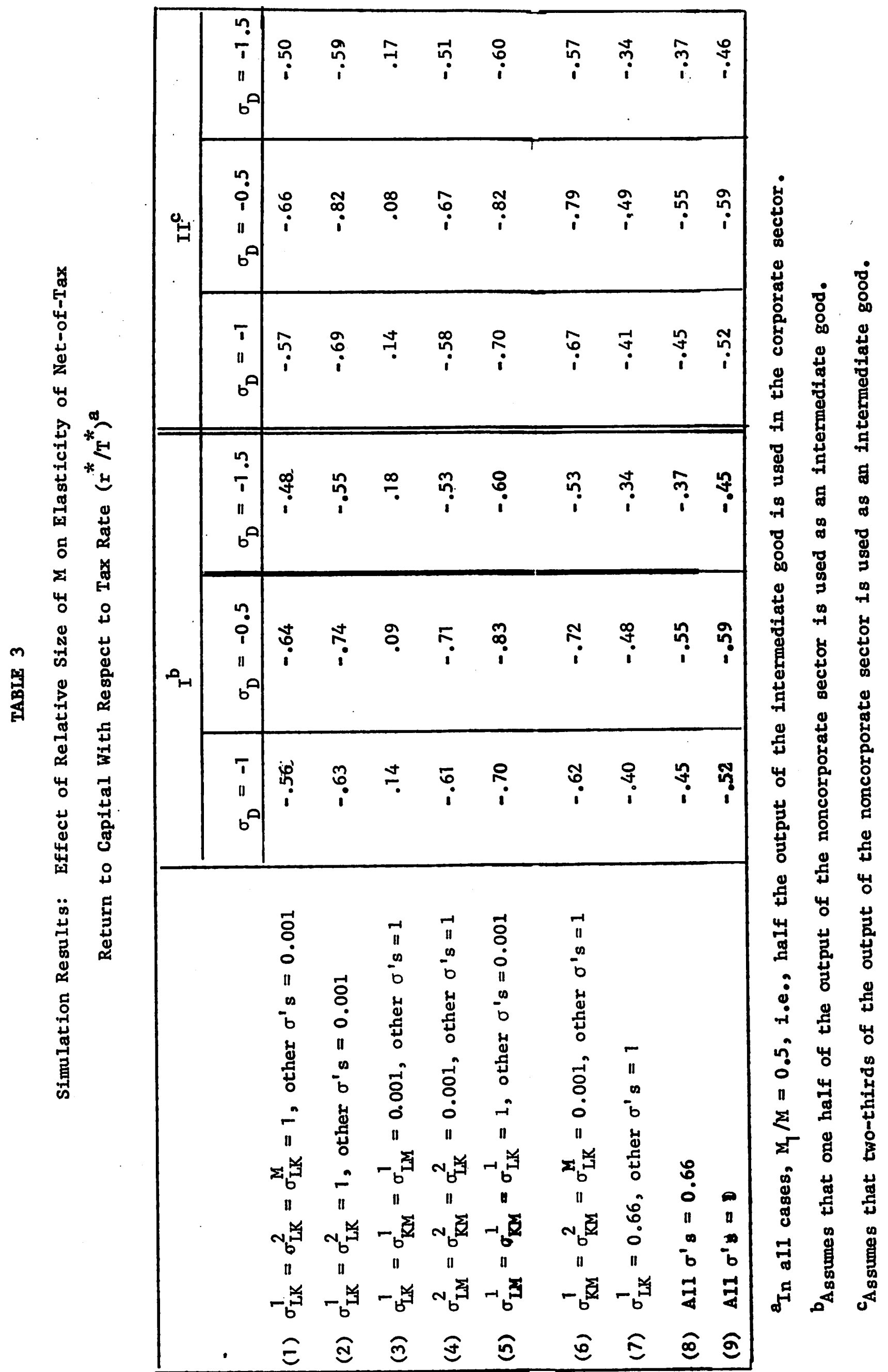




\section{FOOTNOTES}

* University of Western Ontario. It is a pleasure to acknowledge many helpful discussions with R. N. Batra, Chin Iim, and Arthur Robson on this general topic. Glenn Kendall's assistance with some of the empirical results reported in Section IV is also greatly appreciated. A referee's comments on an earlier draft too have improved the paper. The Social Sciences and Humanities Research Council deserves thanks for financial support of the research reported here.

${ }^{1}$ Pure intermediate goods, on which this paper focusses, have not been considered in the tax literature. Some authors--Fullerton, Shoven and Whalley (1978), and Melvin (1979) for example--have used input-output models with fixed coefficients. Primary factors are either left out or assumed to be separable from intermediate goods. No such restrictions are imposed on the production functions in this paper.

${ }^{2}$ Corporations also produce intermediate goods (steel, fertilizer, etc.) and taxes are levied in the noncorporate sector as well. These are left out to keep the analysis within manageable bounds.

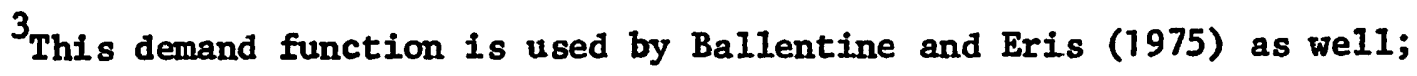
however, because of intermediate goods, subsequent derivation here is quite different from theirs. It is worth noting that in Harberger's original analysis (1962) demand depended only on relative prices, which requires, inter alia, that there are no taxes in the initial situation.

4 Total requirements of primary factors are indicated throughout the paper by $L_{i}$ or $K_{i}$, without primes. For example, total capital used in producing $\mathrm{X}_{1}$ is $\mathrm{K}_{1}=\mathrm{R}_{\mathrm{K} 1} \mathrm{X}_{1}=\mathrm{a}_{\mathrm{K} 1} \mathrm{X}_{1}+\mathrm{a}_{M 1} \mathrm{a}_{\mathrm{KM}} \mathrm{M}=\mathrm{K}_{1}^{\prime}+\frac{\mathrm{M}_{1}}{\mathrm{X}_{1}} \cdot \mathrm{K}_{\mathrm{M}^{\circ}}^{\prime}$. 5or a proof, see Batra (1974), pp. 178-79. 
6 Neary (1978) shows that a necessary and sufficient condition for dynamic stability of distorted factor markets in a similar model (with a slightly different demand curve and no intermediate good) is that expressions such as $\Delta$ be positive. In the present model also, if final goods alone are considered, $\Delta$ will be positive as long as the two industries have the same rank in physical and value terms $(|\lambda|$ and $|\theta|$ have the same sign) but as Herberg and Kemp (1980) point out, $\Delta$ can be positive even when $|\lambda| \cdot|\theta|<0$. It is not clear if these results carry over to a model with intermediate goods. Pending a full-fledged stability analysis of this model, we. shall rely on the empirical evidence cited in the next footnote.

${ }^{7}$ Data presented by Harberger (1962) for 1952-55 show that $\mathrm{K}_{1} / \mathrm{K}_{2}=1$ and $L_{1} / I_{2}$ is equal to about 10 . When intermediate goods are allowed for, gross factor intensities change: $K_{1} / K_{2}=1.2$ and $L_{1} / L_{2}=13.3$, so $A=-12.1$. Ratti and Shome (1977) also find that the U.S. corporate sector is relatively labor intensive: in 1970 the share of labor in corporate industries was 0.8 and only about 0.3 in the non-corporate sector. For the results reported in the next section, $r^{*}$ was computed for a wide $r$ ange of empirically plausible values for $A$ and the $\sigma^{\prime} s$, varying $A$ from -30 to about 1 and $\sigma^{\prime} s$ between 0 and 2 . The denominator of (27) was invariably positive.

8 For a homogeneous production function, with two factors, holding the price of another input constant is the same thing as holding the quantity of that input constant, but not when there are three or more inputs. For an illuminating discussion of this and related matters, see solow (1967). 
9. It assumed that "Miscellaneous Agricultural Products" in Leontief's classification corresponds to "Farms" in Harberger's terminology, and "Agricultural, Forestry and Fishery Services" in the former matches with "Agricultural services, forestry, fisheries" in the latter. Details of other approximations are reported in a short data note available from the author.

10"Miscellaneous agricultural products", "Agricultural, Forestry, and Fishery Services", and "Real Estate and Rental" in Leontief's classification come closest to Harberger's "noncorporate sector", and these industries used roughly half of the output of the intermediate good as defined here. This assumption, however, is not critical. As the simulation results reported in Section $V$ show, estimates of $r^{*}$ are not very sensitive to how $M$ is divided between $x_{1}$ and $x_{2}$.

${ }^{11}$ As Barberger (1962) shows, $\epsilon=\sigma_{D} x_{2} /\left(x_{1}+x_{2}\right)$

${ }^{12}$ The stability condition discussed above requires that no more than one cross-partial elasticity of substitution be zero in each industry. For the results in Table 1, therefore, we approximate fixed proportions by setting the relevant $\sigma_{i j}$ 's equal to 0.001 .

13 These changes are reallocations within the same total national income. When the magnitude of $M$ is increased, the size of $x_{2}$ is reduced. 14 It is worth noting that, as mentioned at the outset of this paper, products of the taxed industry can also be used as intermediate goods, and such goods can sometimes be used as final goods as well. Moreover, there are taxes other than the corporation income tax in the economy. A model incorporating these considerations might yield results which differ from those presented here. 


\section{REFERENCES}

Allen, R. G. D., 1969, Mathematical Analysis for Economists (Macmillan, U.K.). Ballentine, J. G. and I. Eris, 1975, On the General Equilibrium Analysis of Tax Incidence, Journal of Political Economy, 83, 633-44.

Batra, R. N., 1974, Studies in the Pure Theory of International Trade (Macmillan, U.K.).

Blackorby, C. and R. R. Russe11, 1976, Functional structure and the Allen Partial Elasticities of Substitution: An Application of Duality Theory, Review of Economic Studies, 43, 285-91'

Fullerton, D., Shoven, J. and J. Whalley, 1978, General Equilibrium Analysis of U.S. Taxation Policy, in 1978 Compendium of Tax Research (U.S. Treasury Department, Washing ton) 23-63.

Harberger, A. C., 1959, The Corporation Income Tax: An Empirical Appraisal, in U.S. Committee on Ways and Means Tax Revision Compendium (U.S. Government Printing office, Washington) 231-50.

Harberger, A. C., 1962, The Incidence of the Corporation Income Tax, Journal of Political Economy, 70, 215-40.

Herberg, H. and M. C. Kemp, 1980, In Defense of Some "Paradoxes" of Trade Theory, American Economic Review, 70, 812-14.

Jones, R. W., 1971a, Distortions in Factor Markets and the General Equilibrium Model of Production, Journal of Political Economy, 79, 437-59.

Jones, R. W., 1971b, Effective Protection and Substitution, Journal of International Economics, 1, 59-81.

Leontief, W. W., 1965, The Structure of the U.S. Economy, Scientific American, $212,25-35$ 
Melvin, J. R., 1979, Short-Run Price Effects of the Corporation Income Tax and Implications for International Trade, American Economic Review, $69,250-62$.

Neary, J. P., 1978, Dynamic Stability and the Theory of Factor-Market Distortions, American Economic Review, 68, 671-82.

Ratti, R. A. and P. Shome, 1977, The Incidence of the Corporation Income Tax: A Long-Run Specific Factor Mode1, Southern Journal of Economics, 85-98.

Solow, R. M., 1967, Some Recent Developments in the Theory of Production, in: M. Brown, ed., The Theory and Empirical Analysis of Production (National Bureau of Economic Research, New York) 25-50. 